\title{
Electron microscope observations on LH-induced oocyte maturation in Japanese quail (Coturnix coturnix japonica)
}

\author{
Y. Yoshimura, T. Okamoto and T. Tamura \\ Faculty of Applied Biological Science, Hiroshima University, Higashihiroshima 724, Japan
}

\begin{abstract}
The aim of this study was to describe the temporal sequence of ultrastructural changes in the boundary between the preovulatory oocyte and its surrounding follicular wall during maturation induced by injection of LH. Female Japanese quail were injected with ovine $\mathrm{LH}(20 \mu \mathrm{g}$ per bird) 10-12 h before the expected time of ovulation. The largest and second largest follicles were excised before or 1, 2, 4 or $6 \mathrm{~h}$ after injection. The oocyte and the surrounding follicular wall were processed for observations using light and electron microscopy. Before injection of LH, cytoplasmic projections of granulosa cells interdigitated with microvilli on the surface of the oocyte and formed spot desmosomes and gap junctions with the oolemma. Two hours after injection of $\mathrm{LH}$, the germinal vesicles in the largest but not in the second largest follicles began to break down and membrane-bound vesicles increased in number and size in the surrounding germinal disc. The junctions between the oocyte surface and the granulosa cell projections started to dissociate and a perivitelline space began to develop, possibly as the result of an accumulation of fluids transported from the capillary sinus in the theca interna. The first maturation spindle was formed $4 \mathrm{~h}$ after injection of $\mathrm{LH}$, whereas the first polar body and the second maturation spindle were formed $6 \mathrm{~h}$ after LH stimulation. These observations suggest that the dissociation of connections between the oocyte and granulosa cells $2 \mathrm{~h}$ after exposure to increased concentration of $\mathrm{LH}$ is the first process of oocyte maturation. The associated increase in number and enlargement of membrane-bound vesicles in the germinal disc may be involved in the activation of factors involved in oocyte maturation.
\end{abstract}

\section{Introduction}

The germinal disc of the avian oocyte is a thickened mass of protoplasm in the centre of which lies the germinal vesicle adjacent to the oolemma (Olsen and Fraps, 1950). Oocyte maturation is induced by $\mathrm{LH}$ in birds (Olsen and Fraps, 1950) as in mammals and lower vertebrates (Lindner $e$ t al., 1974; Tsafriri et al., 1982; Patino and Thomas, 1990). Germinal vesicle breakdown occurs in the chicken approximately $6 \mathrm{~h}$ before the expected time of ovulation (Olsen and Fraps, 1950), the time when the LH concentration in the blood increases (Johnson and van Tienhoven, 1980). Condensation of chromatin, extrusion of the first polar body and formation of the second maturation spindle are completed $2.5 \mathrm{~h}$ before the expected time of ovulation (Olsen and Fraps, 1950). In quail the interdigitations between the surface membrane of the preovulatory oocyte and its surrounding granulosa cells disintegrate approximately $6 \mathrm{~h}$ before the expected time of ovulation, and the first polar body and second maturation spindle appear $1 \mathrm{~h}$ before the expected time of ovulation during spontaneous oocyte maturation (Yoshimura et al., 1993). In mammals, the immature oocyte forms gap junctions with surrounding cumulus cells, which break down during oocyte maturation (Hyttel et al., 1986;

Received 20 July 1992.
Phillips and Dekel, 1991). There is no evidence for gap junctions between the oocyte and surrounding granulosa cells in birds, although open cytoplasmic communications have been described during the prelampbrush stage in quail follicles (Callebaut, 1991), as is the case in squamate reptiles (Andreuccetti et al., 1978). In the quail, a few hours before ovulation, smooth membrane-bound vesicles are observed in the germinal disc in association with the formation of the second maturation spindle and the first polar body (Yoshimura et al., 1993). The development of these membrane-bound vesicles may be related to the activation of the factors involved in oocyte maturation.

The precise temporal sequence of the ultrastructural changes at the interface between the preovulatory avian oocyte and the follicular wall after LH stimulation has not been described. In particular, details of germinal vesicle breakdown have not been observed because it is difficult to obtain the follicles at the appropriate stage of maturation during a naturally occurring preovulatory release of $\mathrm{LH}$. In this study, the temporal sequence of the ultrastructural changes between the preovulatory oocyte and its surrounding follicular wall were observed before and after administration of LH. Particular note was taken of changes in the junctions between the oocyte and surrounding granulosa cells, the features of germinal vesicle breakdown and the development of membrane-bound vesicles in the germinal disc. 


\section{Materials and Methods}

Female Japanese quails laying five eggs or more in a sequence were maintained in individual cages at a lighting cycle of $14 \mathrm{~h}$ light (from 06:00 h to 20:00 h) and $10 \mathrm{~h}$ darkness, and provided with food and water ad libitum. Ovulation occurs 30-60 min after oviposition and approximately $6 \mathrm{~h}$ after the preovulatory release of LH (Doi et al., 1980). Birds that had the second egg of a sequence in their shell glands were intravenously injected with ovine $\mathrm{LH}(20 \mu \mathrm{g}$ per bird) or vehicle $10-12 \mathrm{~h}$ before the expected time of ovulation (06:00 h). LH (NIADDK-oLH-26) was dissolved in PBS ( $\mathrm{pH}$ 7.4) at a concentration of $200 \mu \mathrm{g} \mathrm{ml}^{-1}$. Birds were killed by decapitation before or 1, 2, 4 or $6 \mathrm{~h}$ after LH or vehicle injection. Each experimental group consisted of 4-7 birds. Immediately after death, the largest and second largest follicles were removed and processed for histological examination. Follicles were fixed in Karnovsky's fixative ( $4 \%$ paraformaldehyde and $5 \%$ glutaraldehyde in Millonig's buffer consisting of $0.12 \mathrm{~mol} \mathrm{NaH}_{2} \mathrm{PO}_{4} \mathrm{l}^{-1}$ and $0.12 \mathrm{~mol} \mathrm{NaOH} \mathrm{l} l^{-1}$, $\mathrm{pH} 7.2)$ at $4^{\circ} \mathrm{C}$ for $1 \mathrm{~h}$. The germinal disc region of the oocyte and associated follicular wall were then cut and refixed overnight in the same fixative at $4^{\circ} \mathrm{C}$. These tissues were then washed with Millonig's buffer for $2 \mathrm{~h}$, followed by post-fixation in $1.3 \%$ osmium tetroxide in Millonig's buffer at $4^{\circ} \mathrm{C}$ for $2 \mathrm{~h}$. Tissues were then dehydrated with acetone and embedded in Epon 812. For light microscope observations thick sections were stained with toluidine blue. Thin sections were stained with uranyl acetate and lead acetate, and examined under JEM $1200 \mathrm{EX}$ electron microscope (JEOL, Japan) at an accelerating voltage of $60 \mathrm{kV}$.

\section{Results}

Before injection of LH the germinal vesicle was located in the centre of the germinal disc adjacent to the oolemma and surrounded with dense protoplasm (Fig. Ia). The germinal vesicle was bounded by a smooth membrane and contained an amorphous matrix with spherical postlampbrush chromosomes (Callebaut, 1973) (Fig. 1b). The oocyte was surrounded by a perivitelline layer and follicular wall consisting of a granulosa layer, theca interna and theca externa (Fig. Ib). No significant structural changes were observed in the germinal vesicle $1 \mathrm{~h}$ after injection of LH. Two hours after injection of $\mathrm{LH}$, the germinal vesicle had shrunk and its membrane had become folded. The cytoplasm surrounding the residue of the germinal vesicle contained no yolk granules but was filled with a lightly stained matrix which may have leaked out of the vesicle (Fig. 2a). Spherical postlampbrush chromosomes were localized in the centre of the degenerating germinal vesicle (Fig. $2 b$ ). The first maturation spindle was located perpendicular to the surface of the germinal disc $4 \mathrm{~h}$ after $\mathrm{LH}$ injection (Fig. 3a). Six hours after LH injection, the first polar body was located in the perivitelline space and the second maturation spindle was observed near the surface of the oolemma (Fig. 3b).

Observations using the electron microscope showed that before injection of $\mathrm{LH}$ the germinal vesicle contained a lightly stained amorphous matrix surrounded by distinct inner and outer nuclear membranes (Fig. 4). Numerous ooplasmic elements including membrane-bound vesicles, oval or elongated mitochondria, Golgi apparatus, glycogen granules and yolk spheres were observed in the protoplasm adjacent to the germinal vesicle (Fig. 4). In the germinal disc distant from the germinal vesicle, numerous membrane-bound vesicles were located near the oolemma with yolk spheres accumulated under them. Cytoplasmic projections of the granulosa cells interdigitated with microvilli on the surface of the oocyte and formed spot desmosomes and gap junctions with the oolemma. The spot desmosomes were characterized by dense plaques just beneath the granulosa cell plasma membrane and oolemma (Fig. 5a), whereas gap junctions were formed by the close apposition of the granulosa cell plasma membrane and oolemma separated by a narrow gap (Fig. 5 b).

Two hours after injection of $\mathrm{LH}$, ultrastructural changes were observed in the oocyte and follicular wall (Fig. 6). Vacuoles were associated with the germinal vesicle membrane and some parts of it were disintegrating. A small number of dense bodies, membrane-bound vesicles and glycogen granules were scattered around the germinal vesicle (Fig. 6). Membrane-bound vesicles were observed in the germinal disc distant from the germinal vesicle that were not observed here before injection of LH (Fig. 7). In four of seven preovulatory follicles, the granulosa cells and the oocyte surface became less tightly associated as shown by development of a wide perivitelline space between the perivitelline membrane and oolemma (Fig. 7). Many oocyte microvilli were erect and not associated with granulosa cell projections. In some cases, gap junctions were still present between the large cytoplasmic processes of granulosa cells and the oolemma (Fig. 7).

Four hours after $\mathrm{LH}$ injection, the membrane-bound vesicles located beneath the oolemma in the germinal disc were greatly distended (Fig. 8). Spot desmosomes and gap junctions between oocyte and granulosa cell membranes were not observed in any of the follicles and were assumed to have disintegrated.

No significant structural changes were observed in oocytes in the second largest follicle of birds injected with LH or in the largest and second largest follicles from birds injected with vehicle.

\section{Discussion}

The present results demonstrate that injection of quail with LH $10-12 \mathrm{~h}$ before ovulation induces oocyte maturation in the largest follicle but not in smaller follicles. This result supports the report that $\mathrm{LH}$ is the primary factor involved in the induction of oocyte maturation in birds (Olsen and Fraps, 1950). However, it remains unclear why only the oocyte in the largest follicle undergoes maturation. In lower vertebrates, progesterone or other steroid hormones produced in the granulosa cells in response to LH may induce oocyte maturation through interaction with specific steroid receptors in the oolemma (Haider, 1990). In chickens, granulosa cells in the mature preovulatory follicle, in contrast to those in smaller follicles, produce large amounts of progesterone in response to LH (Nakamura et al., 1991). The granulosa cells in the largest quail follicle contain prominent paranuclear lipid droplets (Callebaut, 1988; Callebaut et al., 1991), suggesting that they have a steroidogenic function (Van Nassauw and Callebaut, 1991). If progesterone is one of 

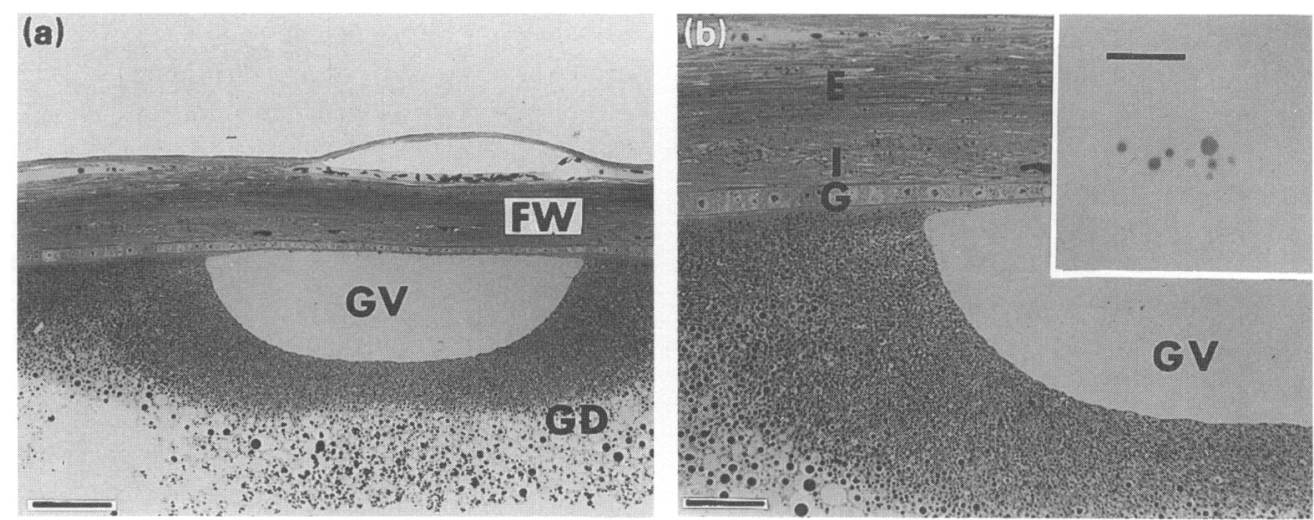

Fig. 1. (a) Light micrograph of a cross-section of the germinal disc of a preovulatory follicle from the Japanese quail $10 \mathrm{~h}$ before the expected time of ovulation and before $\mathrm{LH}$ injection. The germinal vesicle (GV) is located in the centre of the germinal disc (GD). FW: follicular wall. Scale bar $=50 \mu \mathrm{m}$. (b) Magnified view of the section shown in (a). The follicular wall consists of the granulosa layer $(G)$, theca interna (I) and theca externa (E). Scale bar $=25 \mu \mathrm{m}$. Inset shows the postlampbrush chromosomes in the centre of the germinal vesicle. Scale bar $=10 \mu \mathrm{m}$.
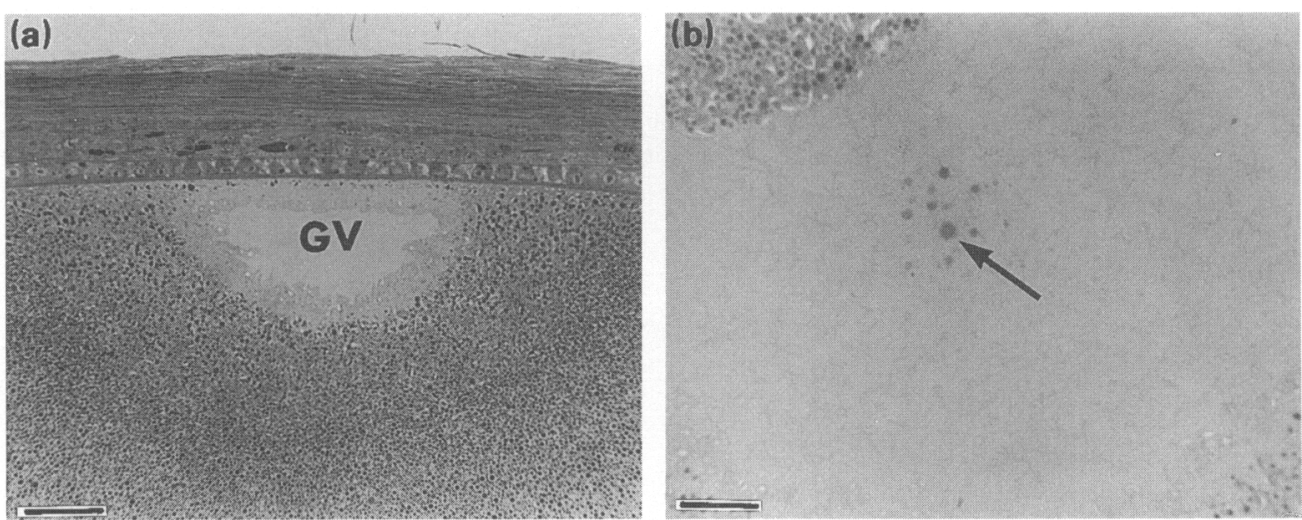

Fig. 2. (a) Light micrograph of a cross-section of the germinal disc $2 \mathrm{~h}$ after $\mathrm{LH}$ injection. The germinal vesicle $(\mathrm{GV})$ is breaking down. Note the folds of the germinal vesicle membrane. Scale bar $=25 \mu \mathrm{m}$. (b) Light micrograph of a cross-section of the germinal vesicle $2 \mathrm{~h}$ after LH injection. The postlampbrush chromosomes (arrow) are still observed in the centre of the germinal vesicle. Scale bar $=10 \mu \mathrm{m}$.
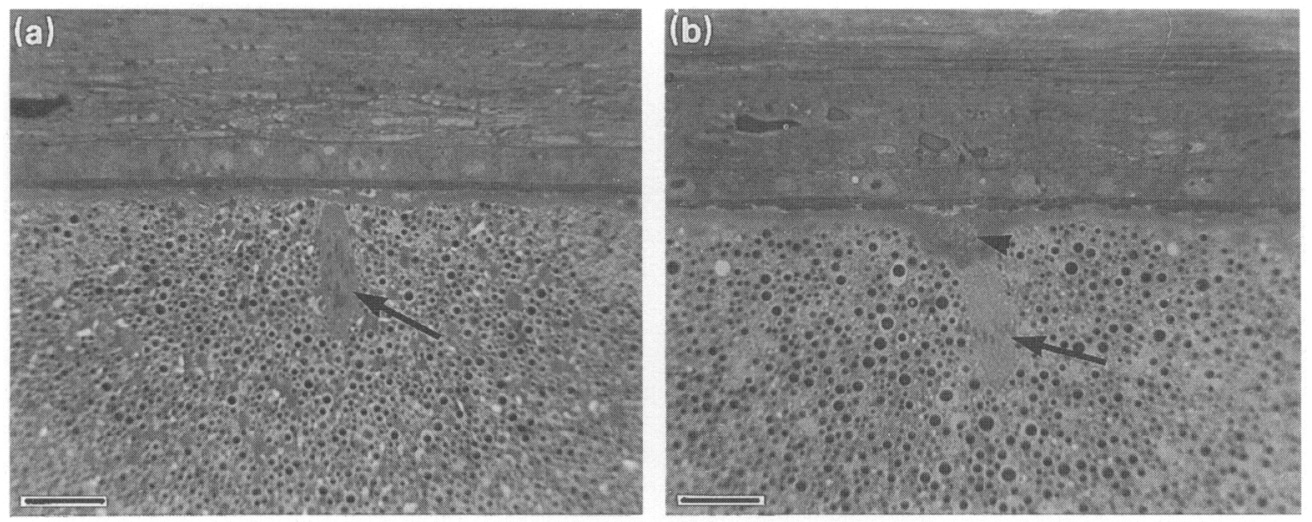

Fig. 3. (a) Light micrograph of a cross-section of the germinal disc $4 \mathrm{~h}$ after LH injection. Note that the first maturation spindle which contains chromosomes is formed (arrow). Scale bar $=10 \mu \mathrm{m}$. (b) Light micrograph of a cross-section of the germinal disc $6 \mathrm{~h}$ after LH injection. Note the second maturation spindle (arrow) and the first polar body (arrowhead). Scale bar $=10 \mu \mathrm{m}$. 


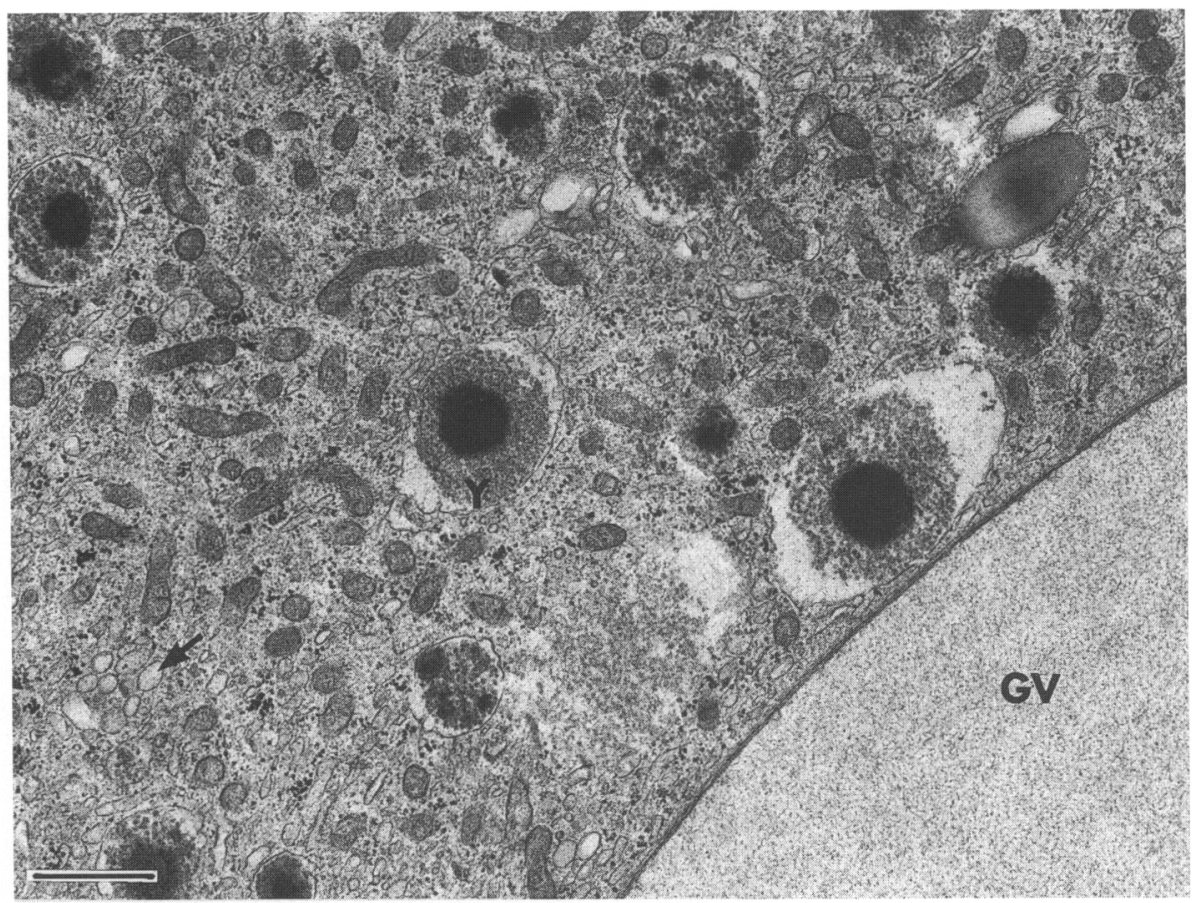

Fig. 4. Electron micrograph of the germinal disc and germinal vesicle $10 \mathrm{~h}$ before the expected time of ovulation and before LH injection. Note that the membrane-bound vesicles (arrow) and numerous cytoplasmic organelles are distributed near the germinal vesicle $(G V)$. Y: yolk sphere. Scale bar $=$ $1 \mu \mathrm{m}$.
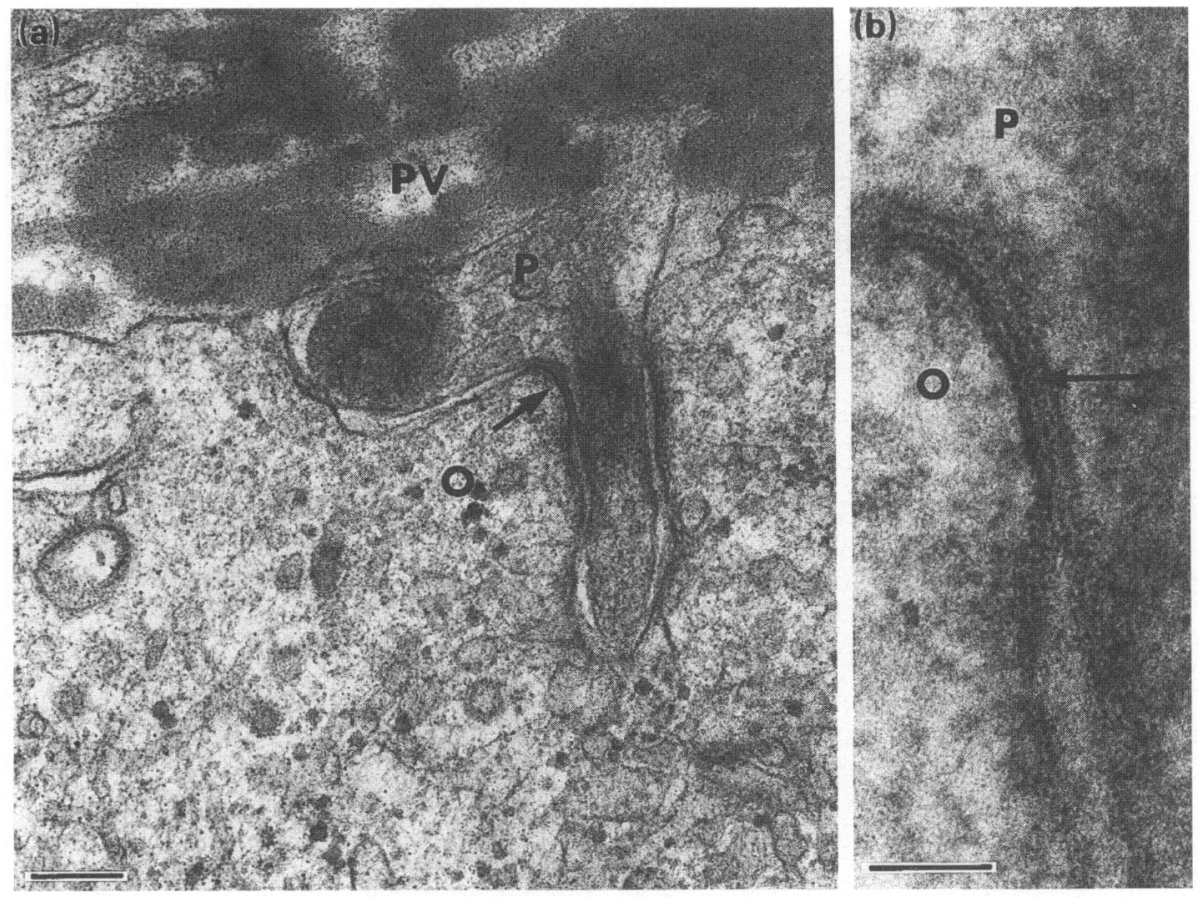

Fig. 5. (a) Electron micrograph of a junction between the granulosa cell projection and the oocyte. Note the close contact of the large cytoplasmic projection of the granulosa cell $(\mathrm{P})$ with the oocyte (arrow). O: oocyte; PV: perivitelline layer. Scale bar $=200 \mathrm{~nm}$. (b) Magnified view of the section shown in (a). Arrow indicates that the close contact of the granulosa cell projection $(\mathrm{P})$ and oolemma is the gap junction. $O$ : oocyte. Scale bar $=50 \mathrm{~nm}$. 


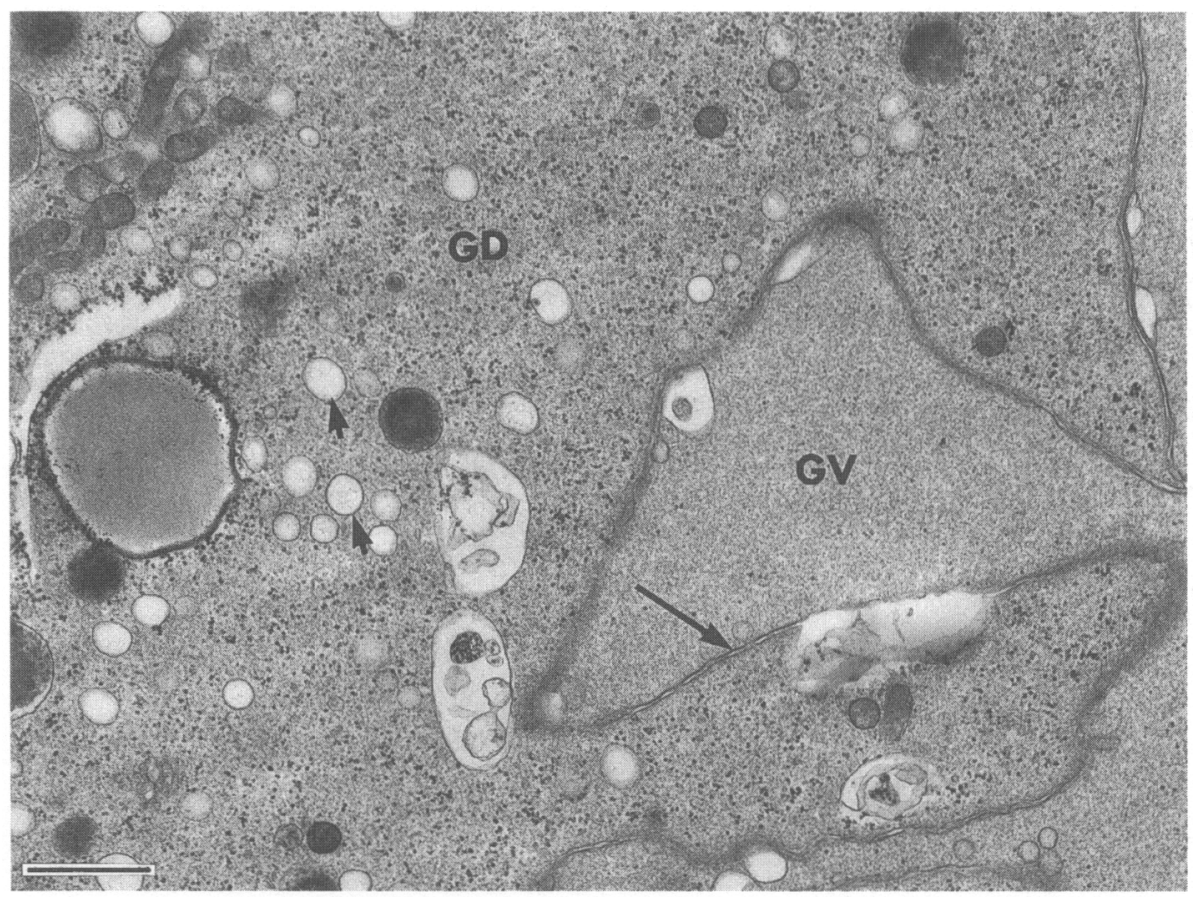

Fig. 6. Electron micrograph of the germinal disc $2 \mathrm{~h}$ after $\mathrm{LH}$ injection. Note the germinal vesicle (GV) which is breaking down. The germinal vesicle membrane (long arrow) shows an irregular appearance, and the vacuoles formed are associated with the germinal vesicle membrane, suggesting that the membrane is digested. Short arrows indicate membrane-bound vesicles that are highly developed compared with those observed before LH injection (Fig. 4). GD: germinal disc. Scale bar $=1 \mu \mathrm{m}$.

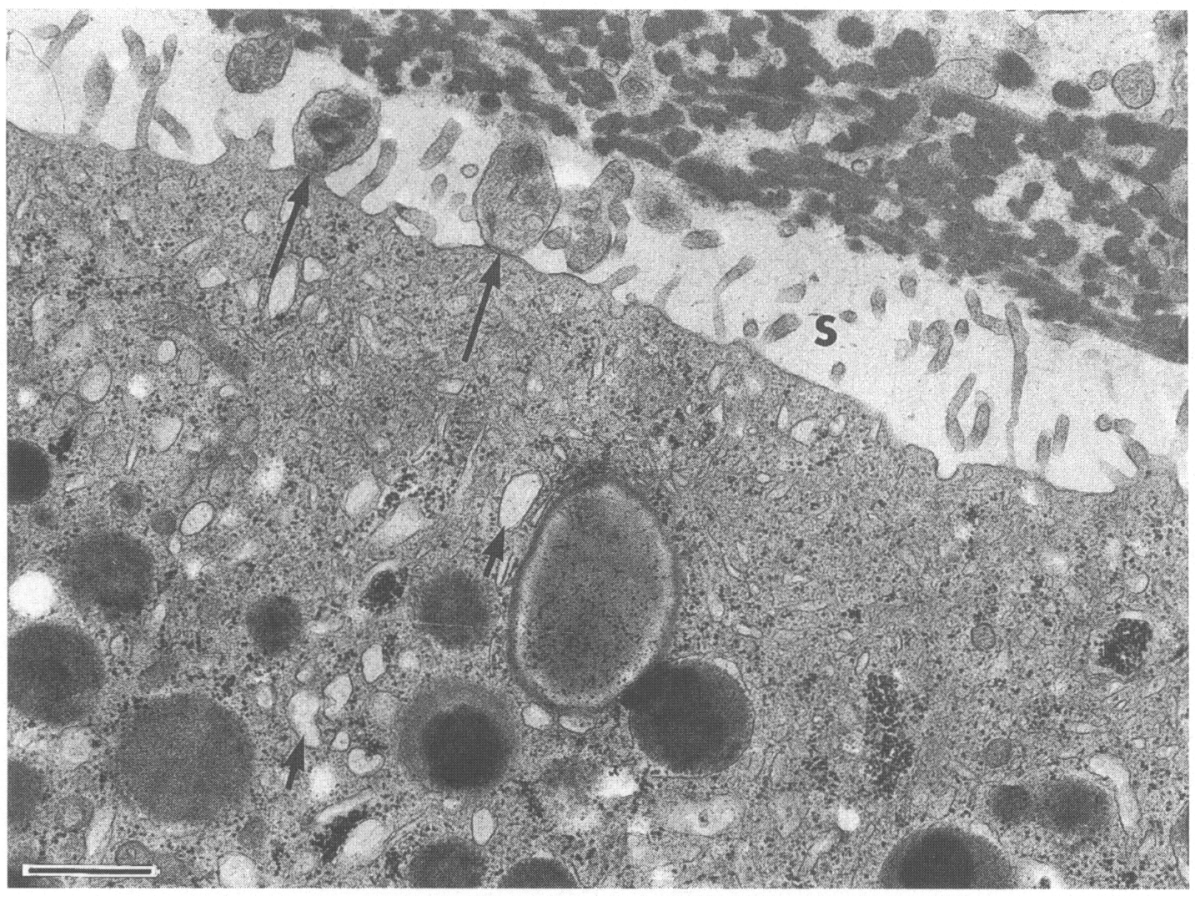

Fig. 7. Electron micrograph of the germinal disc distant from the germinal vesicle $2 \mathrm{~h}$ after LH injection. Note that a wide perivitelline space $(S)$ is formed and the junctions of the granulosa cell projections with the oocyte are dissociated except for a few gap junctions which remain attached (long arrows). Short arrows indicate the developing membrane-bound vesicles. Scale bar $=1 \mu \mathrm{m}$. 


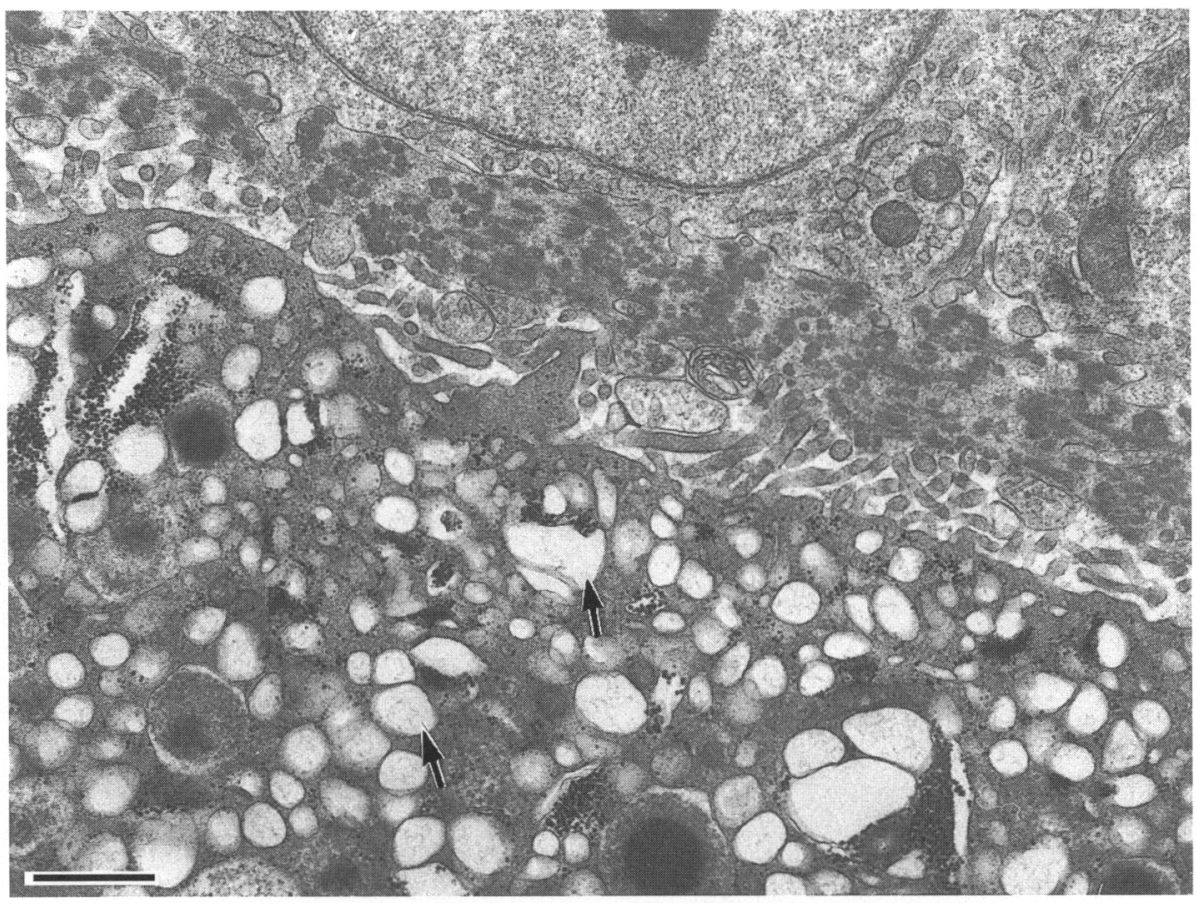

Fig. 8. Electron micrograph of the germinal disc $4 \mathrm{~h}$ after LH injection. Note the markedly developed membrane-bound vesicles (arrows) in the germinal disc. Scale bar $=1 \mu \mathrm{m}$.

the hormones that controls oocyte maturation in hens, the ability of the largest follicle to secrete copious amounts of progesterone may be one of the reasons why $\mathrm{LH}$ induces maturation of the oocyte only in the largest follicle.

It was observed that projections of the granulosa cells form interdigitations, spot desmosomes and gap junctions with the oocyte surface before $\mathrm{LH}$ injection. The interdigitations and spot desmosomes between them have been described by Perry et al. (1978a, b) and Yoshimura et al. (1993), but this is the first report on a bird that demonstrates the presence of gap junctions. The gap junctions between the oocyte and granulosa cells suggest metabolic coupling between them. Two hours after $\mathrm{LH}$ stimulation, these junctions had dissociated with only a few gap junctions remaining in four of the seven follicles examined. This observation confirms our earlier finding that interdigitations between the granulosa cell projections and the preovulatory oocyte break down $6 \mathrm{~h}$ before the expected time of ovulation (Yoshimura et al., 1993). In mammals also, gap junctions between the oolemma and granulosa cells in immature follicles break down during oocyte maturation (Gilula et al., 1978; Hyttel et al., 1986). In mice, channels in gap junctions between the cumulus cell projections and the oocyte may be blocked even though the junctions are not dissociated morphologically during oocyte maturation (Phillips and Dekel, 1991). In the present study, three of the seven follicles did not show significant morphological changes in the junction between the granulosa cells and oocyte $2 \mathrm{~h}$ after $\mathrm{LH}$ injection. Observations by Phillips and Dekel (1991) suggest that the functional coupling of the granulosa cells with the oocyte may have been disrupted in the absence of any visible morphological change in these three follicles.

Studies in mammals suggest that cumulus and granulosa cells produce factors that prevent oocyte maturation after transfer to the oocyte via gap junctions with these cell types (Sato and Koide, 1984; Anderson $e t$ al., 1985; Sirard and Bilodeau, 1990). The metabolic coupling between the cumulus cells and oocyte via gap junctions is terminated at the time of oocyte maturation resulting in the resumption of meiosis (De Loos et al., 1991). It is therefore possible that, in quail, metabolic coupling between granulosa cells and the oocyte may prevent oocyte meiosis in immature follicles. The interruption of this coupling between granulosa cells and the preovulatory oocyte may be the first step in oocyte maturation that occurs during the $2 \mathrm{~h}$ after $\mathrm{LH}$ stimulation.

The formation of a wide perivitelline space between the maturing oocyte and surrounding granulosa cells after $\mathrm{LH}$ stimulation may be induced by an influx of blood serum components from the theca interna (Yoshimura et al, 1993). In mammals, the preovulatory LH surge is thought to induce hyperaemia and increase permeability of the thecal capillary sinus (Espey, 1980). It is possible that LH has a similar action in quail.

Maturation-promoting factor activity is believed to play a key role in the progression of the cells from interphase to metaphase in both meiosis and mitosis (Masui and Markert, 1971; Nurse, 1990) including the process of oocyte maturation (Motlik and Kubelka, 1990). Inactive maturation-promoting factor contained in the immature ooplasm is activated when the oocyte resumes meiosis (Motlik and Kubelka, 1990). In an immunoblotting experiment for maturation-promoting factor in the ovary of quail, Mori et al. (1991) found two bands representing 32 and $34 \mathrm{kDa}$ proteins in immature and mature oocytes. A third band, a protein of approximate molecular mass of $32 \mathrm{kDa}$, which may be an active form of maturation-promoting factor, was found exclusively in the oocyte after germinal vesicle 
breakdown. The present study showed that membrane-bound vesicles were developing in the germinal disc as the germinal vesicle was breaking down $2 \mathrm{~h}$ after $\mathrm{LH}$ injection and that these vesicles were markedly developed after germinal vesicle breakdown $4 \mathrm{~h}$ after $\mathrm{LH}$ injection. Development of the membrane-bound vesicles in the germinal disc also occurs during spontaneous oocyte maturation (Yoshimura et al., 1993). The temporal correlation between the changes of maturationpromoting factor activity and the development of the membranebound vesicles suggests that the development of these vesicles may be related to the activation of maturation-promoting factor.

The present results indicate that germinal vesicle breakdown occurs approximately $2 \mathrm{~h}$ after $\mathrm{LH}$ stimulation. The appearance of vacuoles associated with germinal vesicle membrane breakdown suggests that the membrane may be digested. However, factors responsible for the digestion of germinal vesicle membrane remain unknown. Although it is suggested that maturation-promoting factor or some phosphoproteins are responsible for induction of germinal vesicle breakdown (Thibault et al., 1987; Rime and Ozon, 1990; Haider, 1990; Kang et al., 1991), no evidence has been obtained that these proteins digest the germinal vesicle membrane. It is reported that proteinase activity participates in the process of spindle formation (Hashimoto et al, 1990), but there is no evidence indicating that proteinase activities are involved in the breakdown of the germinal vesicle membrane.

We wish to thank Dr Janice M. Bahr, University of Illinois, for her valuable comments and critical reading of this manuscript. We also wish to thank NIDDK, Baltimore, Maryland, for the generous gift of the ovine $\mathrm{LH}$ used in this study.

\section{References}

Anderson LD, Stone SL and Channing CP (1985) Influence of hormones on the inhibitory activity of oocyte maturation present in conditioned media of porcine granulosa cells Gamete Research 12 119-130

Andreuccetti P, Taddei C and Filosa S (1978) Intercellular bridges between follicle cells and oocyte during the differentiation of follicular epithelium in Lacerta sicula Journal of Cell Science 33 341-350

Callebaut M(1973) Correlation between germinal vesicle and oocyte development in the adult Japanese quail (Coturnix coturnix japonica): a cytochemical and autoradiographic study Journal of Embryology and Experimental Morphology 29 145-157

Callebaut M (1988) Localization of voluminous highly osmiophilic material in the largest ovarian follicles of laying Japanese quails Medical Science Research 16 1307-1309

Callebaut M (1991) Light- and electron-microscopic observations on the relationship between prelampbrush oocytes and surrounding granulosa cells in the laying Japanese quail (Coturnix coturnix japonica) Reproduction Nutrition Développement 31 461-471

Callebaut M, D'herde K, Hermans N and Van Nassauw L (1991) Localization and transport of lipids in the avian ovarian follicular layers and the structural relationship of theca and granulosa to basement membrane Journal of Morphology 209 143-163

De Loos F, Van Maurik P, Van Beneden TH and Kruip TAM (1991) Heterologous cell contacts and metabolic coupling in bovine cumulus oocyte complexes Molecular Reproduction and Development 28 255-259

Doi O, Takai T, Nakamura T and Tanabe $Y(1980)$ Changes in the pituitary and plasma LH, plasma and follicular progesterone and estradiol, and plasma testosterone and estrone concentrations during the ovulatory cycle of the quail (Cotumix coturnix japonica) General and Comparative Endocrinology 41 156-163
Espey LL (1980) Ovulation as an inflammatory reaction - a hypothesis Biology of Reproduction 22 73-106

Gilula NB, Epstein ML and Beers WH (1978) Cell-to-cell communication and ovulation: a study of the cumulus-oocyte complex Journal of Cell Biology $\mathbf{7 8}$ $58-75$

Haider S (1990) Further experimental evidence in support of the involvement of ovarian follicles in oocyte maturation of the Indian catfish, Mystus vittatus General and Comparative Endocrinology 80 80-84

Hashimoto N, Iwashita S, Shoji-Kasai Y, Kishimoto T and Imahori K (1990) Thiol protease inhibitor, E-64-d, prevents spindle formation during mouse oocyte maturation Development Growth and Differentiation 32 197-203

Hyttel P, Callesen H and Greve T (1986) Ultrastructural features of preovulatory oocyte maturation in superovulated cattle Journal of Reproduction and Fertility 76 645-656

Johnson AL and van Tienhoven A (1980) Plasma concentration of six steroids and LH during the ovulatory cycle of the hen, Gallus domesticus Biology of Reproduction 23 386-393

Kang HM, Cho C, Lee K-K, Kwon HB, Kim K and Cho WK (1991) Protein modification by phosphorylation during the process of nuclear membrane dissolution in puromycin-treated mouse oocytes Biology of Reproduction $\mathbf{4 4}$ 590-598

Lindner HR, Tsafriri A, Lieberman ME, Zor U, Koch Y, Bauminger S and Barnea A (1974) Gonadotrophin action on cultured Graafian follicles: induction of maturation division of mammalian oocyte and differentiation of the luteal cell Recent Progress in Hormone Research 30 79-138

Masui Y and Markert CL (1971) Cytoplasmic control of nuclear behavior during meiotic maturation of frog oocytes Joumal of Experimental Zoology 177 129-146

Mori M, Yamashita M, Yoshikuni M, Fukada S and Nagahama Y (1991) Maturationpromoting factor and $\mathrm{p} 34^{\mathrm{cdc} 2}$ kinase during oocyte maturation of the Japanese quail Developmental Biology 146 246-249

Motlik J and Kubelka M (1990) Cell-cycle aspects of growth and maturation of mammalian oocytes Molecular Reproduction and Development 27 366-375

Nakamura T, Funabashi M and Tanabe Y (1991) In vitro studies on steroidogenesis in the presence of pregnenolone as precursors by the follicular tissue of the domestic fowl (Gailus domesticus) Journal of Steroid Biochemistry $\mathbf{3 8}$ $105-110$

Nurse P (1990) Universal control mechanism regulating onset of $M$-phase Nature 344 503-508

Olsen MW and Fraps RM (1950) Maturation changes in the hen's ovum Journal of Experimental Zoology 114 475-489

Patino $R$ and Thomas $\mathbf{P}$ (1990) Effects of gonadotropin on ovarian intrafollicular processes during the development of oocyte maturational competence in a teleost, the Atlantic croaker: evidence for two distinct stages of gonadotropic control of final oocyte maturation Biology of Reproduction 43 818-827

Perry MM, Gilbert AB and Evans AJ (1978a) Electron microscope observations on the ovarian follicle of domestic fowl during the rapid growth phase journal of Anatomy 125 481-497

Perry MM, Gilbert AB and Evans AJ (1978b) The structure of the germinal disc region of the hen's ovarian follicle during the rapid growth phase Journal of Anatomy 127 379-392

Phillips DM and Dekel N (1991) Maturation of the rat cumulus-oocyte complex: structure and function Molecular Reproduction and Development 28 297-306

Rime H and Ozon R (1990) Protein phosphatases are involved in the in vivo activation of histone HI kinase in mouse oocyte Developmental Biology 141 115-122

Sato E and Koide SS (1984) A factor from bovine granulosa cells preventing oocyte maturation Differentiation 26 59-62

Sirard MA and Bilodeau S (1990) Granulosa cells inhibit the resumption of meiosis in bovine oocytes in vitro Biology of Reproduction 43 777-78.3

Thibault C, Szollosi D and Gerard M (1987) Mammalian oocyte maturation Reproduction Nutrition Développement 27 865-896

Tsafriri A, Dekel N and Bar-Anri S (1982) The role of oocyte maturation inhibitor in follicular regulation of oocyte maturation Journal of Reproduction and Fertility 64 541-551

Van Nassauw $\mathbf{L}$ and Callebaut $\mathbf{M}$ (1991) Structural and immunohistochemical aspects of the postovulatory follicle in Japanese quail Anatomical Record 229 $27-30$

Yoshimura Y, Okamoto T and Tamura T (1993) Structural changes of the oocyte and follicular wall during spontaneous maturation in Japanese quail (Coturnix coturnix japonica) Journal of Reproduction and Fertility 97 189-196 